\title{
Hon. Prof. Prof. Univ. Doz. Dipl.-Ing. Dr. mont. HUBERT PRESSLINGER
}

\author{
Bruno Buchmayr, Johannes Schenk und Gerhard Hackl
}

Leoben, Österreich

Online publiziert 10. November 2020

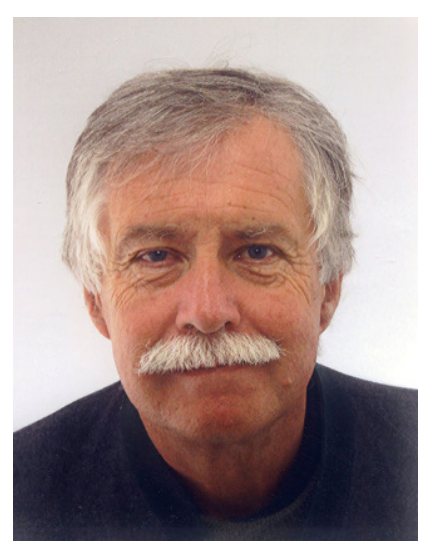

Wir verabschieden uns von einem großartigen Stahlmetallurgen und Montanarchäologen, der am 5. Oktober $2020 \mathrm{im}$ Alter von 71 Jahren unerwartet in Stille verstorben ist.

Hubert Preßlinger wurde am 14. Juli 1949 in Rottenmann geboren. Nach seiner Matura am 1. Bundesgymnasium Graz Carnerigasse und seinem Bundesheerdienst inskribierte er im WS 1970/71 für die Studienrichtung Hüttenwesen an der damals Montanistischen Hochschule in Leoben. Im März 1977 schloss er sein Studium ab und wurde im Juli 1977 als Universitätsassistent am Institut für Eisenhüttenkunde angestellt. Noch im selben Jahr heiratete er seine geliebte Veronika in St. Lorenzen. Bald kam seine Tochter Barbara und später sein Sohn Florian zur Welt.

Im Dezember 1983 schloss er seine Doktorarbeit mit dem Thema „Grundlagen der Entkupferung von Eisenschmelzen mit Sulfatschlacken“ ab. In dem Modellversuch „Wissenschafter für die Wirtschaft" fand er ab September 1985 seine erste industrielle Anstellung bei der VOEST-ALPINE AG im Bereich Forschung, von 2000 bis 2008 war er dort

\footnotetext{
G. Hackl (ه)

Leoben, Österreich

Gerhard.hackl@asmet.org
}

Entwicklungsleiter für Schmelzmetallurgie und Brammenfertigung. Seine wissenschaftlichen Erfolge wurden durch zahlreiche Auszeichnungen, wie dem Hans-Malzacher-Preis der Eisenhütte Österreich, belohnt. Im Jahr 1994 wurde ihm die "venia legendi“ für Metallurgie und Verfahrenstechnik der Stahlerzeugung an der Montanuniversität Leoben erteilt und 2005 wurde ihm der Berufstitel "Universitätsprofessor" durch den Bundespräsident Dr. Heinz Fischer verliehen.

Sein großes Interesse neben der Stahlmetallurgie galt aber der Montanarchäologie. Gemeinsam mit seinem Freund Prof. Clemens Eibner, Professor für Ur- und Frühgeschichte von der Universität Heidelberg, sowie mit seinen Kollegen Gerhard Sperl und Georg Walach führte Hubert Preßlinger erste Grabungen im Paltental durch und gründete den Arbeitskreis Paltental. Zahlreiche Funde wurden werkstoffkundlich untersucht und die schmelzmetallurgischen Prozessabläufe wurden rekonstruiert. Die Produkte aus Kupfer, Bronze und Stahl sowie Keramiken wurden fachgerecht beurteilt und mit dem damaligen Geschehen im obersteirischen Kulturraum in Verbindung gebracht. Im Palten- und Liesingtal konnten 33 urzeitliche und 8 mittelalterliche Kupfer- und einige Eisenerzverhüttungsplätze gefunden werden, die in vielen Publikationen der Öffentlichkeit bekannt gemacht wurden. Insgesamt hat Hubert Preßlinger ca. 160 Veröffentlichungen verfasst, die dem Fachbereich Montangeschichte, Montanarchäologie und Archäometallurgie zugeordnet werden können. Seine Arbeiten beschreiben den Zeitraum von der Keltenzeit und Römerzeit bis zum Hochmittelalter.

Im Jahr 2002 wurde er zum Honorarprofessor der Universität Heidelberg für Ur- und Frühgeschichte mit Schwerpunkt Montanarchäologie und Archäometallurgie ernannt. Im selben Jahr wurde ihm für diese Verdienste das Goldene Ehrenzeichen des Landes Steiermark verliehen.

Wir erinnern uns noch sehr gut an das Symposium „Eisen- und Stahlerzeugung - Gestern, heute und morgen" am 8. November 2019 an der Montanuniversität Leoben, das zu Ehren seines 70. Geburtstages organisiert wurde. In 
seinem Festvortrag beschrieb er die Rolle der bronzezeitlichen Metallurgie als Auslöser zu einer blühenden Industriegesellschaft in der Obersteiermark (nachzulesen in BHM (2020) Vol. 165, H. 9, 428-435).

Allein aus der Aufzählung seiner Leistungen wird klar, wie erfolgreich und wertvoll sein Wirken in den beiden Bereichen Stahlmetallurgie und Montanarchäologie war. Die österreichische Eisen- und Stahlmetallurige verliert einen weit über die Grenzen hinaus anerkannten Forscher. Die zahlreichen Publikationen in unserer Zeitschrift BHM bestätigen auch die enge Verbundenheit zur Eisenhütte Österreich, nun ASMET. In der Ausgabe 09/2020 der BHM, ein Heft mit montanhistorischem Schwerpunkt, sind drei neue Artikel von ihm publiziert, und im nächsten Jahr werden in den BHM zwei weitere Beiträge posthum erscheinen.
Hubert Preßlinger war stets ein ruhiger, zurückhaltender, ja sogar bescheidener Mensch, der trotz seiner Erfolge nicht überheblich war und sehr diszipliniert und fachlich überaus fordernd Schritt für Schritt seinen Lebensweg ging. Er war überaus korrekt, aber auch hilfsbereit, gläubig und für viele ein guter Freund.

Er war aufgrund seines vielfältigen Wirkens immer ein Vorbild und wir werden ihm stets ein ehrendes Andenken bewahren.

Unser aller Mitgefühl und unsere innigste Anteilnahme gelten seinen beiden Kindern Barbara und Florian sowie allen Angehörigen und Freunden.

Fiducit!

Bruno Buchmayr, Johannes Schenk, Gerhard Hackl 